\title{
Electrical Stimulation Enhances Migratory Ability of Transplanted Bone Marrow Stromal Cells in a Rodent Ischemic Stroke Model
}

\author{
Jun Morimoto ${ }^{a}$ Takao Yasuhara ${ }^{a}$ Masahiro Kameda ${ }^{a}$ Michiari Umakoshia \\ Ittetsu Kin ${ }^{a}$ Ken Kuwahara ${ }^{a}$ Kyohei Kin ${ }^{a}$ Mihoko Okazaki ${ }^{a}$ Hayato Takeuchia \\ Tatsuya Sasakia Atsuhiko Toyoshima ${ }^{a}$ Naoki Tajiria, c Takashi Agaria \\ Cesario V. Borlongan ${ }^{b}$ Isao Date ${ }^{a}$ \\ aDepartment of Neurological Surgery, Okayama University Graduate School of Medicine, Kita-ku, \\ Okayama, Japan; b Department of Neurosurgery, University of South Florida Morsani College of \\ Medicine, Tampa, Florida, United States of America; 'Department of Psychology, Graduate School of \\ Psychology, Kibi International University 8 Iga-machi, Takahashi-city, Okayama, Japan
}

\section{Key Words}

BMSCs • Cerebral infarction • Electrical stimulation • Migration • Transplantation

\begin{abstract}
Background/Aims: Bone marrow stromal cells (BMSCs) transplantation is an important strategy for the treatment of ischemic stroke. Currently, there are no effective methods to guide BMSCs toward the targeted site. In this study, we investigated the effect of electrical stimulation on BMSCs migration in an ischemic model of rats. Methods: Adult male Wistar rats weighing 200 to $250 \mathrm{~g}$ received right middle cerebral artery occlusion (MCAO) for 90 minutes. BMSCs $\left(2.5 \times 10^{5}\right.$ cells/ $4 \mu \mathrm{l}$ PBS $)$ were stereotaxically injected into the left corpus callosum at 1 day after MCAO. After BMSCs injection, a plate electrode with a diameter of 3 $\mathrm{mm}$ connected to an implantable electrical stimulator was placed on the right frontal epidural space and a counter electrode was placed in the extra-cranial space. Electrical stimulation at preset current $(100 \mu \mathrm{A})$ and frequency $(100 \mathrm{~Hz})$ was performed for two weeks. Behavioral tests were performed at 1, 4, 8, and 15 days after MCAO using the modified Neurological Severity Score (mNSS) and cylinder test. Rats were euthanized at 15 days after MCAO for evaluation of infarction area and the migration distance and area of BMSCs found in the brain tissue. After evaluating cell migration, we proceeded to explore the mechanisms guiding these observations. MCAO rats without BMSCs transplantation were stimulated with same current and frequency. At 1 and 2 weeks after MCAO, rats were euthanized to evaluate stromal cellderived factor 1 alpha (SDF-1 $\alpha$ ) level of brain tissues in the bilateral cortex and striatum. Results: Behavioral tests at 4, 8, and 15 days after MCAO revealed that stimulation group




\section{Cellular Physiology Cell Physiol Biochem 2018:46:57-68 \begin{tabular}{l|l} 
and Biochemistry Published online: March 23, 2018 & $\begin{array}{l}\text { DOI: } 2018 \text { The Author(s). Published by S. Karger AG, Basel } \\
\text { www.karger.com/cpb }\end{array}$
\end{tabular} \\ Morimoto et al.: Electrical Stimulation Enhances Migration of Tranplanted BMSCs}

displayed significant amelioration in mNSS and cylinder test compared to control group $(p<0.05)$. Similarly, the infarction areas of stroke rats in stimulation group were significantly decreased compared to control group $(p<0.05)$. Migration distance and area of transplanted BMSCs were significantly longer and wider respectively in stimulation group. An increased concentration gradient of SDF-1 $\alpha$ in stimulation group accompanied this enhanced migration of transplanted cells. Conclusions: These results suggest that electrical stimulation enhances migratory ability of transplanted BMSCs in ischemic stroke model of rats. If we can direct the implanted BMSCs to the site of interest, it may lead to a greater therapeutic effect.

(C) 2018 The Author(s)

Published by S. Karger AG, Basel

\section{Introduction}

Ischemic stroke is a major cause of long term disability and mortality in the world because of its high incidence and narrow therapeutic window. Recently, cell transplantation therapy has emerged as a new therapeutic option for ischemic stroke. In particular, bone marrow stromal cells (BMSCs) transplantation is promising therapy [1, 2]. Various studies have been completed concerning BMSCs transplantation route and timing in both basic and clinical studies, yet none of these investigations have explored cell migratory potentials [3-6]. There are currently no effective methods of guiding transplanted cells toward the targeted site. Ischemic stroke itself has the effect of guiding transplanted cells [7-9], however, only a small number of cells reach the ischemic penumbra by trans-arterial transplantation, which is the less invasive method of cell transplantation. Moreover, intravenous transplantation, the least invasive method, delivers even fewer cells due to the majority of transplanted cells being trapped in peripheral organs [10-12]. Although intracerebral transplantation can deliver the entire cell transplant into the targeted site, this method creates a new injury to the brain tissue and cannot distribute the cells widely. The ability to effectively direct a greater number of cells to the ischemic penumbra may allow cell transplantation to become a more potent therapy option.

Independent of transplantation therapies, electrical stimulation has become an important therapeutic strategy for central nervous system disorders such as Parkinson's disease and stroke. There are some reports that electric fields may direct various types of cells in vitro [13-15]. Furthermore, electrical stimulation enhances migration of endogenous neural stem cells and cell proliferation in vivo $[16,17]$. However, to date no in vivo studies exist investigating the ability of electric current to guide the transplanted cells within the ischemic brain.

In this study, we applied electrical simulation to the infarcted hemisphere and examined the migratory ability of transplanted allogenic BMSCs in a rat model of ischemic stroke.

\section{Materials and Methods}

\section{Ethics statement}

This study was conducted in accordance with the guidelines of the Institutional Animal Care and Use Committee of Okayama University Graduate School of Medicine. The protocol was specifically approved by the Institutional Animal Care and Use Committee of Okayama University Graduate School of Medicine (protocol \#OKU- 2015390). Adult male Wistar rats were used in this study. For euthanasia, pentobarbital was used. MCAO was carried out under general anesthesia ( $1 \%$ halothane in $69 \% \mathrm{~N}_{2} \mathrm{O}$ and $30 \% \mathrm{O}_{2}$ ). All efforts were made to minimize suffering animals.

\section{Animals}

Adult male Wistar rats (CLEA JAPAN, Inc., Tokyo, Japan) weighing 200 to $250 \mathrm{~g}$ at the beginning of the experiment were used in this study. They were housed singularly per cage in a temperature and humiditycontrolled room, maintained on a 12-hour light/dark cycle, with free access to food and water. Body weight (BW) was recorded at day $0,1,4,8$ and 15.

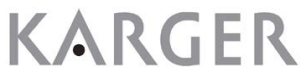




\section{Cellular Physiology Cell Physiol Biochem 2018:46:57-68 \begin{tabular}{ll|l} 
DOI: 10.1159/000488409 & $\begin{array}{l}\text { (c) } 2018 \text { The Author(s). Published by S. Karger AG, Basel } \\
\text { www.karger.com/cpb }\end{array}$
\end{tabular}}

Morimoto et al.: Electrical Stimulation Enhances Migration of Tranplanted BMSCs

\section{Culture of BMSCS}

Rats were euthanized by sodium pentobarbital $(100 \mathrm{mg} / \mathrm{kg})$ with subsequent removal of the femoral bones (n=6). After the femoral bone marrow was flushed, cells were cultured at $2 \times 10^{4} \mathrm{cells} / \mathrm{cm}^{2}$ in DMEM (Gibco, Cergy Pontoise, France) supplemented with $10 \%$ fetal calf serum (Gibco) and $1 \%$ (v/v) penicillin/ streptomycin (Gibco). Cells were cultured at $37{ }^{\circ} \mathrm{C}$ in a fully humidified atmosphere with $10 \% \mathrm{CO}_{2}$. The medium was changed twice a week. In the present study, we used BMSCs after 3 passages.

\section{Surgical procedures}

Transient Middle Cerebral Artery Occlusion. MCAO was carried out according to the intraluminal suture method used in our previous study [18-20]. Under general anesthesia (1\% halothane in $69 \% \mathrm{~N}_{2} \mathrm{O}$ and $30 \% \mathrm{O}_{2}$ ) and a 4-0 monofilament nylon suture with silicone-coated tip (Xantopren L blue \& ACTIVATOR Universal Liquid, Heraeus Kulzer GmbH \& Co. KG, Hanau, Germany) was inserted through an arteriotomy of the right common carotid artery into the right MCA. After MCAO for 90 minutes, the filament was withdrawn and common carotid artery was ligated with 3-0 silk suture.

Cell labeling and intra-cerebral BMSC transplantation. Before cell transplantation, BMSCs were labeled with Q-Tracker 625 Cell Labeling kit (Q-dot nanocrystal, a red fluorescent marker; Invitrogen, Carlsbad, CA) for characterization of BMSCs according to the manufacturer's protocol. Once the BMSCs were cultured using Q-Tracker 625 Cell Labeling kit, Q-dot nanocrystals were delivered into the cytoplasm of BMSCs. Thereafter, the cells were detached with $0.05 \%$ trypsin-EDTA, and $2.5 \times 10^{5}$ cells were diluted with $4 \mu \mathrm{L}$ of phosphate-buffered saline (PBS). The procedure of intracerebral transplantation in rats was as follows: At 1 day after MCAO, the rats were deeply anesthetized with pentobarbital (35 mg/kg, intraperitoneally) and placed in a stereotaxic instrument (Narishige, Tokyo, Japan). Approximately $2.5 \times 10^{5}$ BMSCs in $4 \mu \mathrm{L}$ PBS was injected into the left corpus callosum with a $24 \mathrm{G}$ Hamilton syringe. The injection coordinates were anteriorposterior (AP) $1 \mathrm{~mm}$ from the bregma, mediolateral (ML) $2.5 \mathrm{~mm}$ to the sagittal suture, and dorsoventral (DV) $2.5 \mathrm{~mm}$ from the dura.

Electrode implantation and electrical stimulation. Following the cell transplantation, craniectomy (3.5 $\mathrm{mm} \times 3.5 \mathrm{~mm}$ ) was performed at the rightfrontal bone which centered on anterior $1.00 \mathrm{~mm}$ and lateral $2.5 \mathrm{~mm}$ from the bregma. Subsequently, a disc electrode with a diameter of $3 \mathrm{~mm}$ was implanted on the right frontal epidural space and which was embedded in the skull with dental cement. A counter electrode was placed in the extra-cranial space. The electrode was connected to an implantable pulse generator unit (ISE1000SA; UNIMEC, Tokyo, Japan). All the systems were embedded under the skin. Rats were randomly divided into the stimulation group $(\mathrm{n}=10)$, and control group $(n=8)$. The home cage of the rats was placed on a stimulation commander (ISE1010C; UNIMEC) which was connected to an electronic

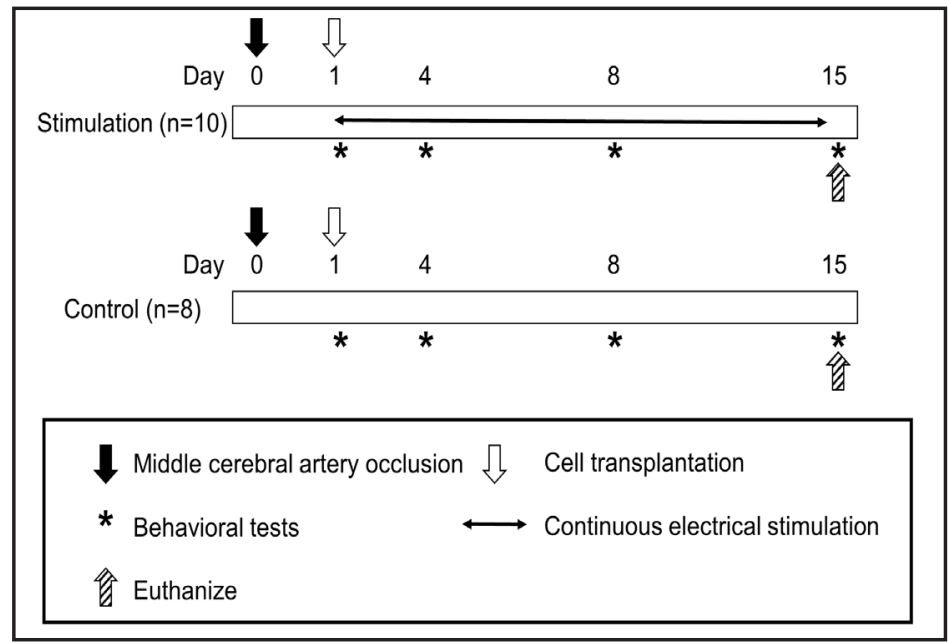

Fig. 1. Experimental design for cell migration analysis. Schematic diagram showing experimental design for cell migration. Rats were performed right MCAO at day 0. And the next day, BMSCs were transplanted into left corpus callosum after behavioral tests. After cell transplantation, stimulation electrode was placed on the right epidural space in stimulation group $(n=10)$ and continuous electrical stimulation was performed from day 1 to day 15 . Rats in control group $(n=8)$ were also placed the same stimulation system, but were not stimulated. At day 15, rats were euthanized and performed histological analysis. 


\section{Cellular Physiology Cell Physiol Biochem 2018;46:57-68

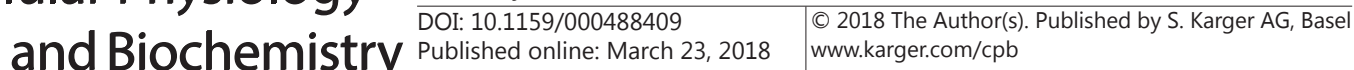 \\ Morimoto et al.: Electrical Stimulation Enhances Migration of Tranplanted BMSCs}

stimulator and isolator (SEN-7203 and SS-202J; NIHON KOHDEN, Tokyo, Japan). The stimulation system allows the rats to move freely in their home cage within the electrical stimulation. Rats of the stimulation group were continuously stimulated for 2 weeks after electrode implantation. Stimulating pulses were square-wave pulses and preset at the duration of $100 \mu \mathrm{s}$ constant current. The parameter of stimulating pulses was adjusted to the preset current $(100 \mu \mathrm{A})$ and frequency $(100 \mathrm{~Hz})$. The stimulation pulses were checked by analog-to-digital converter and software (PowerLab 8/30 and Chart5; AD Instruments, Dunedin, New Zealand). We used a monopolar setting to reduce the risk of tissue damage and to stimulate more diffusely $[16,21]$. After the 2 weeks of stimulation, the electric stimulation was discontinued (Fig. 1).

\section{Behavioral tests}

mNSS. Behavioral testing was performed at day 0, 1, 4, 8 and 15 using the modified Neurological Severity Score (mNSS) and cylinder test $(n=18)$. The mNSS was used to assess motor function, sensory disturbance, reflex, and balance. In this score, one score point is awarded for the inability to perform the test or for the lack of reflex. Therefore, the higher score indicates more severe injury. Neurological function was graded on a scale of 0 to 18 (normal score: 0; maximal deficit score: 18) [22-24]. Only rats showing 7-12 points in the mNSS 1 day post-reperfusion were used in this study.

Cylinder test. The cylinder test was performed the same timing as mNSS to assess the degree of forepaw asymmetry. Rats were placed in a transparent cylinder (diameter: $20 \mathrm{~cm}$, height: $30 \mathrm{~cm}$ ) for 3 minutes and the number of forepaw contacts to the cylinder wall was counted. The score of cylinder test in this study was calculated as a contralateral bias, that is, [(the number of contacts with the non-paretic limb)-(the number of contacts with the paretic limb)/ (the number of total contacts) $\times 100]$ [25-28]. The behavioral tests were performed by the two co-authors blind to the group of rats.

\section{Histological analysis}

Measurement of the infarction area. All rats were euthanized with overdosed pentobarbital (100 $\mathrm{mg} / \mathrm{kg}$ ) at 2 weeks after MCAO, and perfused transcardially with $200 \mathrm{ml}$ of cold PBS and $200 \mathrm{ml}$ of $4 \%$ paraformaldehyde (PFA) in PBS. Brains were removed and post-fixed in the same fixative overnight at 4 ${ }^{\circ} \mathrm{C}$, and subsequently stored in $30 \%$ sucrose in PBS until completely submerged. Coronal sections were cut at $30-\mu \mathrm{m}$ thickness with a freezing microtome $\left(-20^{\circ} \mathrm{C}\right)$. These sections were mounted onto slides and Nissl stain was performed to detect infarction area [29]. Infarction area was measured at the site of cell transplantation using a computerized image analysis (Image J; National Institutes of Health, Bethesda, USA). We evaluated infarction area ratio by the following method: infarction area ratio = LT-(RT-RI) / LT\%, where LT is the area of the left hemisphere in $\mathrm{mm}^{2}$, RT is the area of the right hemisphere in $\mathrm{mm}^{2}$ and RI is the infarction area in $\mathrm{mm}^{2}[19,23,30]$.

Measurement of cell migration. Cell migration was assessed at each $30-\mu \mathrm{m}$ coronal sections between $360 \mu \mathrm{m}$ anterior and posterior to the cell transplantation site. These sections were counterstained with 4, 6-diamidino-2-phenylindole (DAPI) and visualized with fluorescence microscopy (Keyence, Osaka, Japan) to detect MSCs labeled by Q-dot $(n=12)$. At the point of histological analysis, 4 rats of stimulation group and 2 rats of control group were excluded. Because there were spilled BMSCs at the brain surface. Therefore, twelve rats were enrolled in migration assessment. Maximum migration distance was defined as the distance between cells transplanted site $(2500 \mu \mathrm{m}$ to the left from the midline) of the section and the most migrated Q-dot and DAPI double positive cell. Maximum migration area was defined as the area of polygon which formed by connecting the distributed Q-dot and DAPI double positive cells with lines in a section. This area was measured at two slices $-360 \mu \mathrm{m}$ anterior and posterior to the cell transplantation site. The average area of anterior and posterior slices was calculated and evaluated. Maximum migration distance and area were also measured using Image J.

Immunohistochemistry for C-X-C chemokine receptor type 4 (CXCR4). In order to explore the expression of CXCR4 in transplanted BMSCs, immunohistochemistry was performed. Coronal section of cell transplantation was used. Sections were washed five times for $3 \mathrm{~min}$ in PBS. For CXCR4 staining, sections were incubated overnight at $4{ }^{\circ} \mathrm{C}$ with rabbit anti CXCR4 antibody (1:500; Abcam, Cambridge, USA) with $10 \%$ normal horse serum and washed five times in PBS. Sections were then incubated with corresponding secondary antibodies; Alexa fluor 488 fragment of goat anti-rabbit IgG $(H+L)(1: 500$; Thermo Fisher Scientific) for 1 hour at 4 degrees $C$ in a dark chamber after several rinses with PBS, followed by DAPI 0.5 $\mathrm{mg} / \mathrm{mL}$ ) for $5 \mathrm{~min}$. The sections were extensively washed with PBS, cover-slipped, and then visualized with 
Fig. 2. Experimental design for SDF-1 $\alpha$ analysis. Schematic diagram showing experimental design for SDF- $1 \alpha$ analysis. Rats were divided into 1 week group (each $\mathrm{n}=7$, both stimulation and control) and 2 weeks group (each $\mathrm{n}=7$, both stimulation and control). They were performed right MCAO at day 0 . And the next day, no BMSCs were transplanted. Then, rats in stimulation group were placed electrode on right epidural space and continuous electrical stimulation was performed until

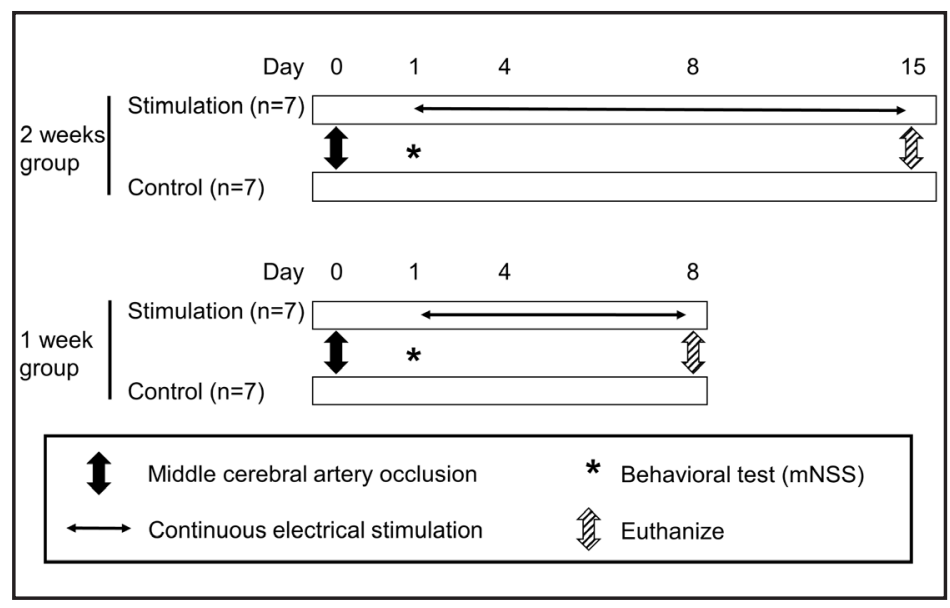
day 8 or day15. Rats in control group were also placed the same stimulation system, but were not stimulated. At day 8 or day 15 , rats were euthanized.

fluorescence microscopy. Next, we evaluated the CXCR4 expression of transplanted BMSCs in each group $(n=4)$.

\section{Enzyme-linked immunosorbent assay (ELISA)}

To assess the efficacy of electrical stimulation on the rat's brain, we performed ELISA analysis. Rats were performed right MCAO at day $0(n=28)$. And the next day, they were randomly divided into 1 week group (each $n=7$, both stimulation and control) and 2 weeks group (each $n=7$, both stimulation and control) after mNSS assessment. Then, rats in stimulation group were placed electrode on the right epidural space and continuous electrical stimulation was performed until day 8 (1 week group) or day15 (2 weeks group). Rats in control group were also placed the same stimulation system, but were not stimulated. At day 8 or day 15, rats were euthanized and performed ELISA analysis for stromal cell-derived factor 1 alpha (SDF-1 $\alpha$ ) (Fig. 2). In this experiment of ELISA analysis, rats were not received BMSCs transplantation to exclude the trophic effect of BMSCs. Brains from rats were quickly removed after decapitation using anesthesia with overdosed pentobarbital (100 mg/kg, i.p.). Brains were sliced at the thickness of $3 \mathrm{~mm}$. The brain tissues of the bilateral cortex and striatum were punched out using a biopsy punch tool $(3 \mathrm{~mm}$ hole, Kai Corporation and Kai industries co., ltd, Tokyo, Japan). Brain tissues were then homogenized in N-PER (Thermo Fisher Scientific, Waltham, USA) with Protease Inhibitor Cocktail (Sigma-Aldrich, St. Louis, USA), centrifuged at $10,000 \mathrm{rpm}$ for 10 minutes at $4{ }^{\circ} \mathrm{C}$ and the supernatant was obtained. The SDF- $1 \alpha$ levels of tissues were measured with a SDF-1 $\alpha$ ELISA assay kit (R\&D Systems, Minneapolis, USA)

\section{Statistical Analyses}

Data were analyzed using IBM SPSS Statistics version 20.0 (IBM, Armonk, USA) and presented as the means \pm standard deviations. The data of BW, mNSS and cylinder test were statistically evaluated using repeated measures ANOVA. The data of histology, infarction area and ELISA were evaluated using Student's t-test. Statistical significance was preset at a $\mathrm{p}$ value $<0.05$.

\section{Results}

\section{$B W$}

Body weight was reduced at day 1 , and displayed a tendency to increase up to 15 days in both control and stimulation group (Fig. 3A). There was no significant difference of body weight between rats in stimulation and control groups (repeated measure ANOVA; F ${ }_{(1,16)}$ $=0.650, \mathrm{p}=0.432$ ). 
Fig. 3. Body weight and behavioral tests of stimulation and control groups. A: The results of body weight are shown. There was no significant difference of body weight between control and stimulation groups. $(\mathrm{n}=8$ in control group and 10 in stimulation group, the mean \pm SD, *p value $<0.05$ ). B: The results of mNSS are shown. Stimulation group showed significant amelioration in mNSS at 4,7 and 15 days $(n=8$ in control group and 10 in stimulation group, the mean \pm SD, $*$ p value $<0.05$ ). C: The results of contralateral bias in the cylinder test. Stimulation group

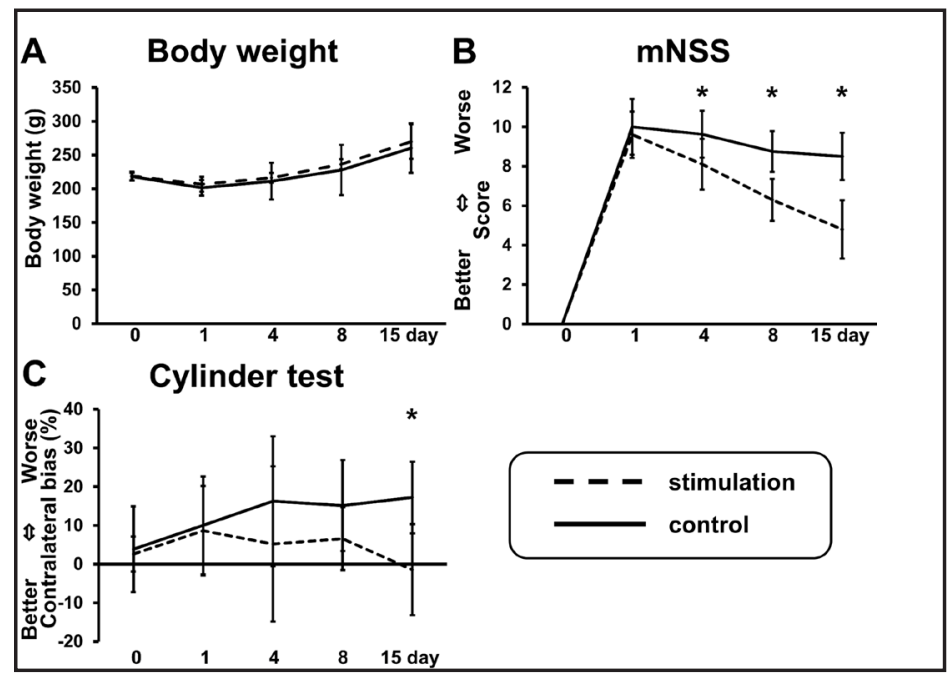
significantly ameliorated stroke induced motor deficits compared to control group at 15 days (n=8 in control group and 10 in stimulation group, the mean \pm SD, *p value<0.05).

Fig. 4. Infarction area. A: Fig. shows Nissl stain of infarcted brain tissue. We calculated the infarction area ratio. Infarction area ratio $=$ LT- $($ RT-RI) $/$ LT\%, where LT is the area of the left hemisphere, RT is the area of the right hemisphere and RI is the infarction area in $\mathrm{mm}^{2}$ at the level of the transplant tract. B: Bar graph showing infarction area ratio in each group. The infarction area ratio of rats in stimulation
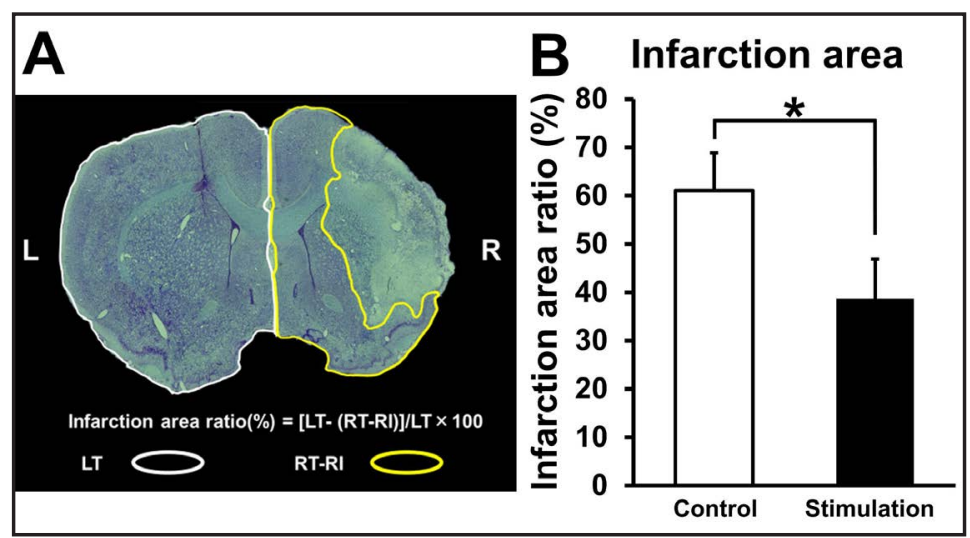
group significantly decreased compared to rats in control group at 15 days after MCAO $(n=8$ in control group and 10 in stimulation group, the mean $\pm S D$, * $p$ value $<0.05$ ).

\section{Behavioral tests}

mNSS. ANOVA revealed significant treatment effects in mNSS (repeated measure ANOVA; $\mathrm{F}_{(1,16)}=27.853$, $\mathrm{p}<0.001$; Fig. 3B). There was no significant difference in the mNSS evaluation between stimulation group and control group at day 0 and 1 . Functional improvement was observed in the stimulation group compared to the control group at day 4 (control group: $9.6 \pm 1.2$; stimulation group: $8.1 \pm 1.3, p=0.020$, respectively), day 7 (control group: $8.8 \pm$ 1.0; stimulation group: $6.3 \pm 1.1, \mathrm{p}<0.001$, respectively) and day 15 (control group: $8.5 \pm 1.2$; stimulation group: $4.8 \pm 1.5$, $\mathrm{p}<0.001$, respectively).

Cylinder test. Rats in the stimulation group appeared to perform better in the cylinder test than those in control groups. ANOVA revealed significant treatment effects in cylinder test (repeated measure ANOVA; $F_{(1,16)}=9.701, p=0.007$; Fig. $3 \mathrm{C}$ ). At day 15, the stimulation group significantly improved in the cylinder test compared to the control group (control group $17.24 \pm 9.27 \%$; stimulation group $-1.43 \pm 11.76 \%$, p=0.002, respectively). 


\section{Cellular Physiology Cell Physiol Biochem 2018;46:57-68

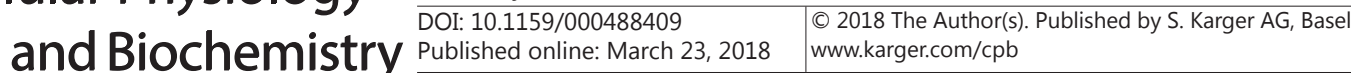 Morimoto et al.: Electrical Stimulation Enhances Migration of Tranplanted BMSCs}

Fig. 5. Migration of implanted BMSCs. A: Photographs of rats in control group and stimulation group taken by fluorescence microscope. White arrows show the most migrated Q-dot and DAPI double positive cell of each section (scale bar: $300 \mu \mathrm{m}$ ). B: Photographs of fluorescence microscopy of rats in control group and stimulation group. White arrows show the most migrated Q-dot and DAPI double positive cells of each section. The polygon drawn with yellow lines was made by connecting the distributed cells of each section (scale bar: $300 \mu \mathrm{m}$ ). C: Bar graph showing migration distances in each group. The migration distance of the stimulation group was significantly extended compared to the control group (each $\mathrm{n}=6$, the mean $\pm \mathrm{SD},{ }^{*}$ p value<0.05). D: Bar graph showing migration areas in each group. The migration area of the stimulation group was significantly extended compared to the control group (each $n=6$, the mean $\pm S D$, * p value $<0.05$ ).

\section{Infarction area}

Figure 4A shows Nissl stain of infarcted brain tissue and infarction area ratio.
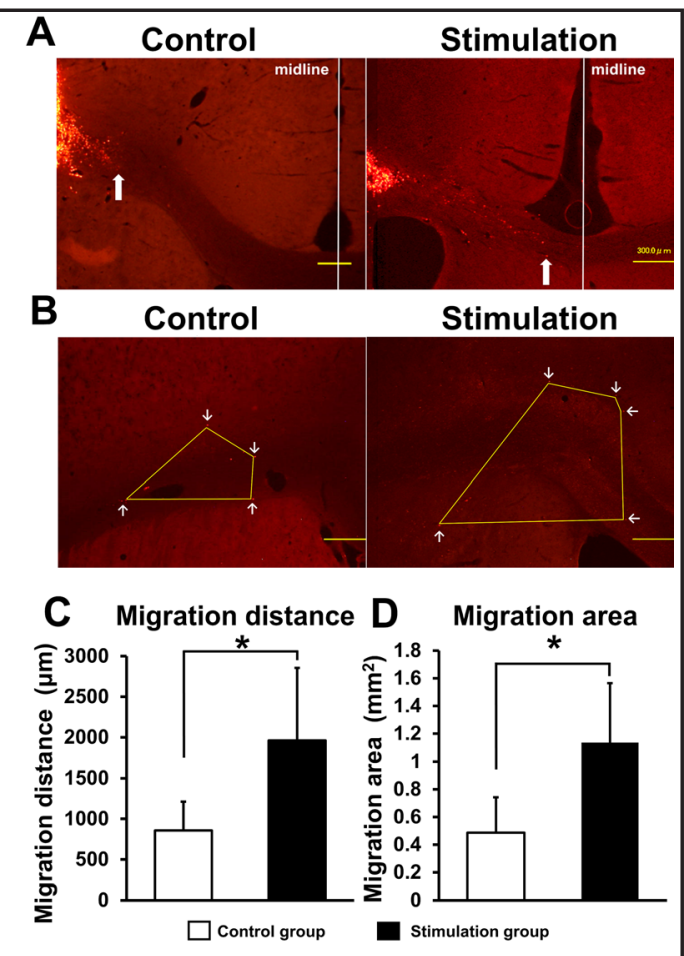
Infarction area of stroke rats in stimulation group were significantly decreased compared to control group (control group $64.5 \pm 12.0 \%$; stimulation group $36.2 \pm 9.9 \%$, p $<0.001$, respectively; Fig. 4B).

\section{Migration of implanted BMSCs}

Migration distance of transplanted BMSCs was significantly extended in stimulation group compared to control group (control group $856.5 \pm 355.4 \mu \mathrm{m}$; stimulation group 1961.2 $\pm 894.1 \mu \mathrm{m}, \mathrm{p}=0.016$, respectively; Fig. 5A, C). Similarly, migration area of transplanted BMSCs was significantly extended in stimulation group (control group $0.49 \pm 026 \mathrm{~mm}^{2}$; stimulation group $1.14 \pm 0.43 \mathrm{~mm}^{2}, \mathrm{p}=0.025$, respectively; Fig. 5B, D).

\section{Immunohistochemistry for CXCR4}

Transplanted BMSCs were expressed CXCR4 in both control and stimulation group (Fig. $6 \mathrm{~A}, \mathrm{~B})$.

\section{ELISA analysis}

The SDF- $1 \alpha$ levels were increased in the right (infarcted) cortex and striatum of rats in both stimulation and control groups, but there were no significant differences between the two groups. However only in the 1 week stimulation group, there was significant difference in SDF- $1 \alpha$ levels between the right (infarcted) and left (intact) hemisphere. That is, SDF-1 concentration gradient of stimulation group (stimulation side > non-stimulation side) was significantly larger than that of control group. Both the cortex and the striatum of 1 week stimulation group showed significant concentration gradients of the SDF- $1 \alpha$ (right cortex $1.19 \pm 0.30 \mathrm{ng} / \mathrm{ml}$; left cortex $0.81 \pm 0.20 \mathrm{ng} / \mathrm{ml}, \mathrm{p}=0.015$, right striatum $1.44 \pm 0.41 \mathrm{ng} / \mathrm{ml}$; left striatum $0.92 \pm 0.20 \mathrm{ng} / \mathrm{ml}, \mathrm{p}=0.011$, respectively; Fig. 7A). In the 2 weeks stimulation group, there were no statistical differences in left versus right or stimulation versus control groups (Fig. 7B). In comparing SDF-1 $\alpha$ data within the stimulated groups between the two different time points, the SDF- $1 \alpha$ level tended to be higher in the infarcted hemisphere (Fig. $8 \mathrm{~A}, \mathrm{~B})$, especially in the right striatum, which displayed a significant elevation of the SDF- $1 \alpha$ level at 1 week compared to 2 weeks ( 1 week $1.44 \pm 0.41 \mathrm{ng} / \mathrm{ml} ; 2$ weeks $0.91 \pm 0.31 \mathrm{ng} / \mathrm{ml}$, $\mathrm{p}=0.019$, respectively; Fig. $8 \mathrm{~B}$ ). 
Fig. 6. Immunohistochemistry for CXCR4. Coronal sections of cell transplanted site was used to assess CXCR4 expression. Fig. showing transplanted Q-dot-labeled BMSCs co-stained with CXCR4. CXCR4 was positive in both control group (A) and stimulation group (B) (each $n=2$, scale bar: $100 \mu \mathrm{m})$.

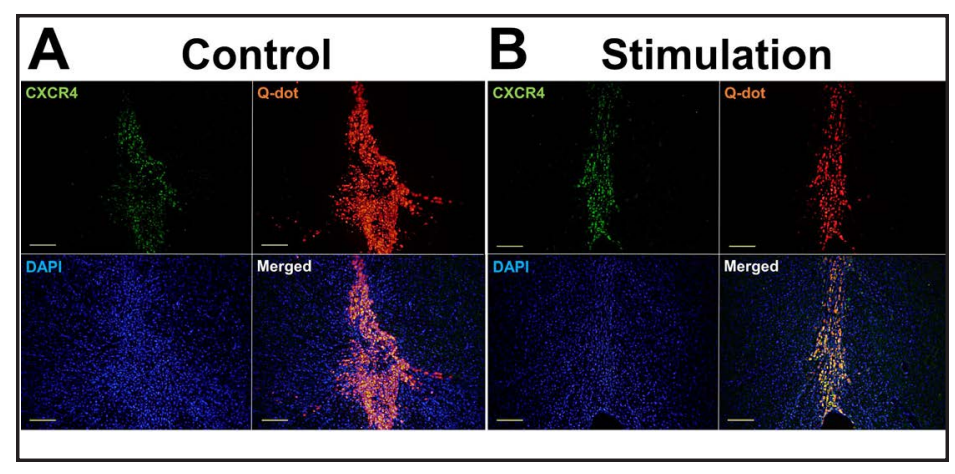

Fig. 7. Results of ELISA analysis for brain SDF-1 $\alpha$ concentration of 1 and 2 weeks group. A: In the 1 week group, only stimulation group showed statistically significant left-right difference of the SDF- $1 \alpha$ level at both of the cortex and the striatum (each $n=7$, the mean $\pm S D, * p$ value< 0.05 ). B: In the 2 weeks group, There were no statistical differences in left and right or stimulation and control group (each $n=7$, the mean $\pm S D$, ${ }^{*}$ p value<0.05).

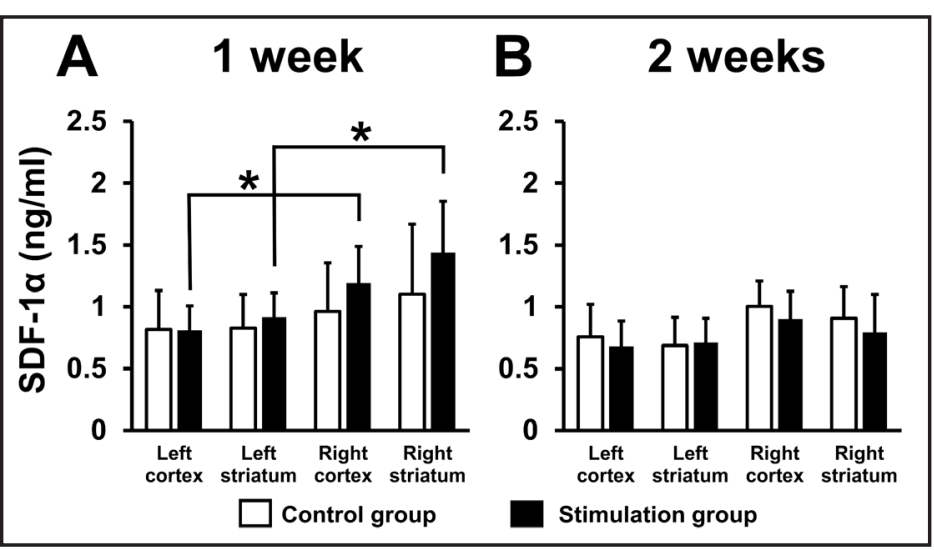

\section{Discussion}

The present study demonstrated that epidural cathodal electrical stimulation on the rat model of ischemic stroke treated with BMSCs transplantation enhanced migratory ability of transplanted cells. The rats in the stimulation group showed a decrease of brain infarction area and functional amelioration. In stimulation group, the SDF- $1 \alpha$ concentration gradient was significantly larger than that of non-stimulation group.

\section{Electrotaxis of cells in vitro}

Some studies have indicated that direct current electrical fields or electrical stimulation enhance migratory ability of various type of cells like NSCs and MSCs in vitro [13-15]. In the present study, BMSCs implanted in the contralateral corpus callosum migrated towards the epidural cathode electrode. Reports exist suggesting that human bone marrow-derived MSCs showed strong anodal electrotaxis, whereas rat bone marrow derived MSCs migrated towards the cathode side [15]. As mentioned previously, direction of cell migration is celltype specific. The mechanism of electrotaxis has been reported to be the result of an influx of $\mathrm{Ca} 2+$ on the anodal side and a decrease of $\mathrm{Ca} 2+$ concentration on the cathodal side, making cell movement toward the cathodal side. However, the existence of voltage-gated $\mathrm{Ca} 2+$ channel on the cell will change the direction of cell movement [31]. This may explain the difference of migration direction and/or speed by various cell types.

\section{Electrotaxis of cells in vivo}

Electrotaxis was also demonstrated by in vivo studies. Epidural stimulation of the motor cortex enhanced neurogenesis in the subventricular zone (SVZ) and migration of endogenous cell to the stimulated cortex. Some of migrated cells have expressed the neural phenotype $[16,17]$. Similarly, in the transcranial direct current stimulation (tDCS), cathodal

\section{KARGER}


Fig. 8. Comparison of the SDF- $1 \alpha$ level in 1 and 2 weeks. A: Bar graph showing the SDF- $1 \alpha$ level of control group. In the control group, the SDF- $1 \alpha$ level tended to increase in 1 week group compared to 2 weeks group. But there was no statistical difference between both groups (each $\mathrm{n}=7$, the mean $\pm \mathrm{SD},{ }^{*} \mathrm{p}$ value $<0.05$ ). B: Bar graph showing the SDF- $1 \alpha$ level of simulation group. In the stimulation group, there was statistically significant difference in 1 and 2 weeks at right

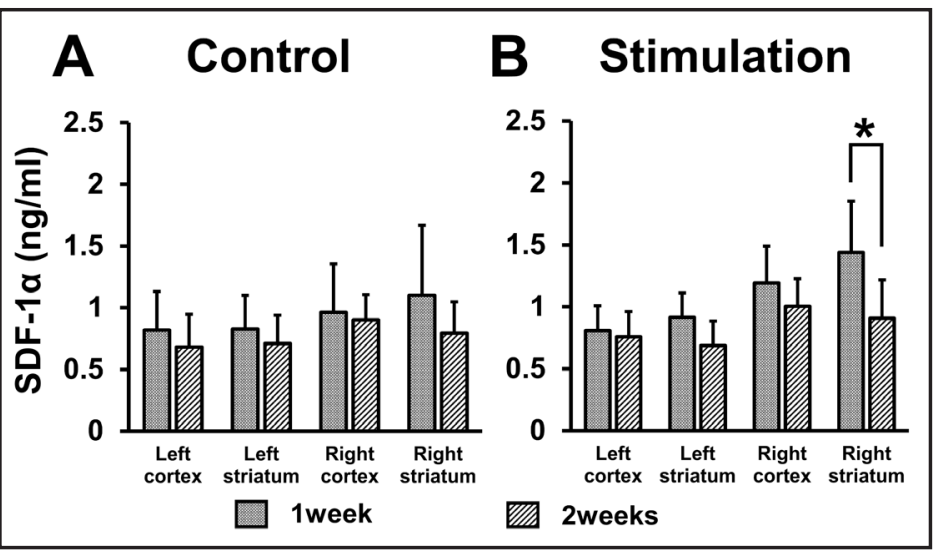
striatum (each $n=7$, the mean $\pm S D$, ${ }^{*}$ v value $<0.05$ ).

stimulation induces the recruitment of proliferating neural stem cells [32]. For migration of transplanted cells, Keuters reported that tDCS promotes the mobility of cells [33]. In our study, migration area of the transplanted cells was also wider in the stimulation group. This suggests that electrical stimulation enhances not only directional migration, but also unidirectional migration of transplanted cells. On the other hand, because of circumjacent tissue construction in vivo and possibility of less migratory ability of transplanted cells, directed migratory activity of transplanted cells was not strongly affected by tDCS [33]. As suggested above, the mechanism of the enhanced migratory ability in this study is likely not only electrotaxis; there may exist other mechanisms that enhance migratory ability of transplanted cells.

\section{SDF-1 $\alpha$ concentration gradient}

In the rat model of ischemic stroke, locally produced SDF- $1 \alpha$ and CXCR4 expressed on the BMSCs surface plays a critical role in the migration of transplanted BMSCs [34-36]. In this study, SDF- $1 \alpha$ concentration gradient of stimulation group was significantly larger than that of non-stimulated group. BMSCs are known to express CXCR4 [37], and transplanted BMSCs of both control and stimulation group expressed CXCR4 in this study. CXCR4 positive cells migrate towards the gradient of SDF-1 $\alpha$ in vitro [38]. In vivo, pre-differentiated cerebellar neurons, which express CXCR4, migrate along the SDF-1 $\alpha$ gradient [39]. This study demonstrated that electrical stimulation increases SDF- $1 \alpha$ concentration gradient (stimulation side $>$ non-stimulation side). It suggests that increased SDF- $1 \alpha$ concentration may play a vital role in migration of transplanted BMSCs.

\section{Expression time of SDF-1 $\alpha$}

In the ischemic brain, the expression of SDF- $1 \alpha$ peaks within a few days, and is upregulated up to 14 days $[36,40]$. Here, the concentration of SDF- $1 \alpha$ was significantly higher at 1 week compared to 2 weeks in the right striatum of stimulation group. This suggests that electrical stimulation increased the expression of SDF- $1 \alpha$ a few days after ischemic stroke. While electrical simulation enhances expression of various cytokines like a vascular endothelial growth factor (VEGF), Glial cell line-derived neurotrophic factor (GDNF) and brain-derived neurotrophic factor (BDNF) $[18,41]$, there are no reports about the effect of electrostimulation on expression of SDF- $1 \alpha$ in the brain. Interestingly, the expression of SDF-1 $\alpha$ was significantly increased in the anal sphincter of rats immediately after 1 hour of electrical simulation [42]. This suggests that expression of SDF-1 $\alpha$ may be enhanced in brain tissues at an earlier stage. Regarding expression of SDF-1 $\alpha$, it may be sufficient to stimulate for a short period in the acute phase. 


\section{Cellular Physiology Cell Physiol Biochem 2018;46:57-68 \begin{tabular}{l|l} 
DOI: 10.1159/000488409 & $\begin{array}{l}\text { (c) } 2018 \text { The Author(s). Published by S. Karger AG, Basel } \\
\text { www.karger.com/cpb }\end{array}$
\end{tabular}

\section{Electrical stimulation ameliorates motor function}

In the stimulation group, functional recovery was significantly enhanced and infarction area significantly decreased. In the very-acute phase of ischemic stroke, it has been reported that cathodal electrical stimulation has neuroprotective effect and decreases the infarction area by reducing cellular depolarization [43]. Cathodal electrical stimulation also preserves cortical neurons and promotes functional recovery [44]. In addition, we used implantable electrical stimulator which can stimulate rats continuously and allow rats to move freely in their home cages. A combination of electrical stimulation and rehabilitation is thought to augment these endogenous plasticity processes $[45,46]$. Therefore, rats may have showed more amelioration of motor function due to the merit of stimulation system used in this study.

\section{Conclusion}

This study demonstrates that electrical stimulation enhances the migratory ability of transplanted bone marrow stromal cells in a rat model of ischemic stroke. Our results suggest that electrical stimulation promotes not only electrotaxis of transplanted cells, but also chemotaxis in the ischemic stroke brain. The increased SDF- $1 \alpha$ concentration gradient is at least one reason for enhanced migration of BMSCs by electrical stimulation.

\section{Acknowledgements}

We thank Masako Arao and Yoshie Ukai for technical assistance in the conduct of the experiments, and Marci Crowley and Michael Liska for help in manuscript preparation. Author contributions are as follows: conceived and designed the experiments: JM, TY, TA and ID; performed the experiments: JM, MU, IK, KK, KK, MO, HT, TS and AT; analyzed the data: JM, TY and CVB; contributed reagents/materials/analysis tools: JM, TY, and ID, wrote the manuscript: JM, TY, NT, ID and CVB.

\section{Disclosure Statement}

No conflict of interests exists.

\section{References}

1 Shinozuka K, Dailey T, Tajiri N, Ishikawa H, Kaneko Y, Borlongan CV: Stem cell transplantation for neuroprotection in stroke. Brain Sci 2013;3:239-261.

2 Steinberg GK, Kondziolka D, Wechsler LR, Lunsford LD, Coburn ML, Billigen JB, Kim AS, Johnson JN, Bates D, King B, Case C, McGrogan M, Yankee EW, Schwartz NE: Clinical Outcomes of Transplanted Modified Bone Marrow-Derived Mesenchymal Stem Cells in Stroke: A Phase 1/2a Study. Stroke 2016;47:1817-1824.

- Kawabori M, Kuroda S, Sugiyama T, Ito M, Shichinohe H, Houkin K, Kuge Y, Tamaki N: Intracerebral, but not intravenous, transplantation of bone marrow stromal cells enhances functional recovery in rat cerebral infarct: an optical imaging study. Neuropathology 2012;32:217-226.

4 Moniche F, Gonzalez A, Gonzalez-Marcos JR, Carmona M, Pinero P, Espigado I, Garcia-Solis D, Cayuela A, Montaner J, Boada C, Rosell A, Jimenez MD, Mayol A, Gil-Peralta A: Intra-arterial bone marrow mononuclear cells in ischemic stroke: a pilot clinical trial. Stroke 2012;43:2242-2244.

5 Shichinohe H, Ishihara T, Takahashi K, Tanaka Y, Miyamoto M, Yamauchi T, Saito H, Takemoto H, Houkin $\mathrm{K}$, Kuroda S: Bone marrow stromal cells rescue ischemic brain by trophic effects and phenotypic change toward neural cells. Neurorehabil Neural Repair 2015;29:80-89.

6 Wan H, Li F, Zhu L, Wang J, Yang Z, Pan Y: Update on therapeutic mechanism for bone marrow stromal cells in ischemic stroke. J Mol Neurosci 2014;52:177-185.

7 Lee JB, Kuroda S, Shichinohe H, Ikeda J, Seki T, Hida K, Tada M, Sawada K, Iwasaki Y: Migration and differentiation of nuclear fluorescence-labeled bone marrow stromal cells after transplantation into cerebral infarct and spinal cord injury in mice. Neuropathology 2003;23:169-180. 


\section{Cellular Physiology Cell Physiol Biochem 2018;46:57-68

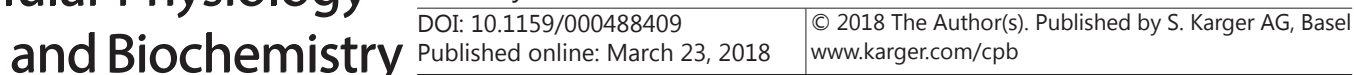 \\ Morimoto et al.: Electrical Stimulation Enhances Migration of Tranplanted BMSCs}

8 Modo M, Mellodew K, Cash D, Fraser SE, Meade TJ, Price J, Williams SC: Mapping transplanted stem cell migration after a stroke: a serial, in vivo magnetic resonance imaging study. Neuroimage 2004;21:311-317.

-9 Shichinohe H, Yamauchi T, Saito H, Houkin K, Kuroda S: Bone marrow stromal cell transplantation enhances recovery of motor function after lacunar stroke in rats. Acta Neurobiol Exp (Wars) 2013;73:354-363.

10 Eggenhofer E, Benseler V, Kroemer A, Popp FC, Geissler EK, Schlitt HJ, Baan CC, Dahlke MH, Hoogduijn MJ: Mesenchymal stem cells are short-lived and do not migrate beyond the lungs after intravenous infusion. Front Immunol 2012;3:297.

11 Guzman R, Choi R, Gera A, De Los Angeles A, Andres RH, Steinberg GK: Intravascular cell replacement therapy for stroke. Neurosurg Focus 2008;24:E15.

-12 Marquez-Curtis LA, Janowska-Wieczorek A: Enhancing the migration ability of mesenchymal stromal cells by targeting the SDF-1/CXCR4 axis. Biomed Res Int 2013;2013:561098.

13 Babona-Pilipos R, Popovic MR, Morshead CM: A galvanotaxis assay for analysis of neural precursor cell migration kinetics in an externally applied direct current electric field. J Vis Exp 2012

14 Li Y, Weiss M, Yao L: Directed migration of embryonic stem cell-derived neural cells in an applied electric field. Stem Cell Rev 2014;10:653-662.

15 Zhao Z, Watt C, Karystinou A, Roelofs AJ, McCaig CD, Gibson IR, De Bari C: Directed migration of human bone marrow mesenchymal stem cells in a physiological direct current electric field. Eur Cell Mater 2011;22:344-358.

16 Jahanshahi A, Schonfeld L, Janssen ML, Hescham S, Kocabicak E, Steinbusch HW, van Overbeeke JJ, Temel Y: Electrical stimulation of the motor cortex enhances progenitor cell migration in the adult rat brain. Exp Brain Res 2013;231:165-177.

17 Kang C, Yang CY, Kim JH, Moon SK, Lee S, Park SA, Han EH, Zhang LQ: The effect of continuous epidural electrical stimulation on neuronal proliferation in cerebral ischemic rats. Ann Rehabil Med 2013;37:301310.

18 Baba T, Kameda M, Yasuhara T, Morimoto T, Kondo A, Shingo T, Tajiri N, Wang F, Miyoshi Y, Borlongan CV, Matsumae M, Date I: Electrical stimulation of the cerebral cortex exerts antiapoptotic, angiogenic, and antiinflammatory effects in ischemic stroke rats through phosphoinositide 3-kinase/Akt signaling pathway. Stroke 2009;40:e598-605.

19 Kameda M, Shingo T, Takahashi K, Muraoka K, Kurozumi K, Yasuhara T, Maruo T, Tsuboi T, Uozumi T, Matsui T, Miyoshi Y, Hamada H, Date I: Adult neural stem and progenitor cells modified to secrete GDNF can protect, migrate and integrate after intracerebral transplantation in rats with transient forebrain ischemia. Eur J Neurosci 2007;26:1462-1478.

20 Sato K, Kameda M, Yasuhara T, Agari T, Baba T, Wang F, Shinko A, Wakamori T, Toyoshima A, Takeuchi H, Sasaki T, Sasada S, Kondo A, Borlongan CV, Matsumae M, Date I: Neuroprotective effects of liraglutide for stroke model of rats. Int J Mol Sci 2013;14:21513-21524.

-21 Temel Y, Visser-Vandewalle V, van der Wolf M, Spincemaille GH, Desbonnet L, Hoogland G, Steinbusch HW: Monopolar versus bipolar high frequency stimulation in the rat subthalamic nucleus: differences in histological damage. Neurosci Lett 2004;367:92-96.

22 Chen J, Sanberg PR, Li Y, Wang L, Lu M, Willing AE, Sanchez-Ramos J, Chopp M: Intravenous administration of human umbilical cord blood reduces behavioral deficits after stroke in rats. Stroke 2001;32:2682-2688.

-23 Toyoshima A, Yasuhara T, Kameda M, Morimoto J, Takeuchi H, Wang F, Sasaki T, Sasada S, Shinko A, Wakamori T, Okazaki M, Kondo A, Agari T, Borlongan CV, Date I: Intra-Arterial Transplantation of Allogeneic Mesenchymal Stem Cells Mounts Neuroprotective Effects in a Transient Ischemic Stroke Model in Rats: Analyses of Therapeutic Time Window and Its Mechanisms. PLoS One 2015;10:e0127302.

24 Wakabayashi K, Nagai A, Sheikh AM, Shiota Y, Narantuya D, Watanabe T, Masuda J, Kobayashi S, Kim SU, Yamaguchi S: Transplantation of human mesenchymal stem cells promotes functional improvement and increased expression of neurotrophic factors in a rat focal cerebral ischemia model. J Neurosci Res 2010;88:1017-1025.

-25 Roof RL, Schielke GP, Ren X, Hall ED: A comparison of long-term functional outcome after 2 middle cerebral artery occlusion models in rats. Stroke 2001;32:2648-2657.

-26 Sasaki T, Liu K, Agari T, Yasuhara T, Morimoto J, Okazaki M, Takeuchi H, Toyoshima A, Sasada S, Shinko A, Kondo A, Kameda M, Miyazaki I, Asanuma M, Borlongan CV, Nishibori M, Date I: Anti-high mobility group box 1 antibody exerts neuroprotection in a rat model of Parkinson's disease. Exp Neurol 2016;275:220231. 


\section{Cellular Physiology Cell Physiol Biochem 2018;46:57-68 \begin{tabular}{c|c|c} 
DOI: 10.1159/000488409 & C 2018 The Author(s). Published by S. Karger AG, Basel \\
www.kargercom/cpb
\end{tabular} \\ Morimoto et al.: Electrical Stimulation Enhances Migration of Tranplanted BMSCs}

27 Schallert T, Fleming SM, Leasure JL, Tillerson JL, Bland ST: CNS plasticity and assessment of forelimb sensorimotor outcome in unilateral rat models of stroke, cortical ablation, parkinsonism and spinal cord injury. Neuropharmacology 2000;39:777-787.

28 Shinko A, Agari T, Kameda M, Yasuhara T, Kondo A, Tayra JT, Sato K, Sasaki T, Sasada S, Takeuchi H, Wakamori T, Borlongan CV, Date I: Spinal cord stimulation exerts neuroprotective effects against experimental Parkinson's disease. PLoS One 2014;9:e101468.

29 Popp A, Jaenisch N, Witte OW, Frahm C: Identification of ischemic regions in a rat model of stroke. PLoS One 2009;4:e4764.

-30 Neumann-Haefelin T, Kastrup A, de Crespigny A, Yenari MA, Ringer T, Sun GH, Moseley ME: Serial MRI after transient focal cerebral ischemia in rats: dynamics of tissue injury, blood-brain barrier damage, and edema formation. Stroke 2000;31:1965-1972; discussion 1972-1963.

-31 Mycielska ME, Djamgoz MB: Cellular mechanisms of direct-current electric field effects: galvanotaxis and metastatic disease. J Cell Sci 2004;117:1631-1639.

-32 Rueger MA, Keuters MH, Walberer M, Braun R, Klein R, Sparing R, Fink GR, Graf R, Schroeter M: Multisession transcranial direct current stimulation (tDCS) elicits inflammatory and regenerative processes in the rat brain. PLoS One 2012;7:e43776.

33 Keuters MH, Aswendt M, Tennstaedt A, Wiedermann D, Pikhovych A, Rotthues S, Fink GR, Schroeter M, Hoehn M, Rueger MA: Transcranial direct current stimulation promotes the mobility of engrafted NSCs in the rat brain. NMR Biomed 2015;28:231-239.

-34 Borlongan CV, Glover LE, Tajiri N, Kaneko Y, Freeman TB: The great migration of bone marrow-derived stem cells toward the ischemic brain: therapeutic implications for stroke and other neurological disorders. Prog Neurobiol 2011;95:213-228.

-35 Shichinohe H, Kuroda S, Yano S, Hida K, Iwasaki Y: Role of SDF-1/CXCR4 system in survival and migration of bone marrow stromal cells after transplantation into mice cerebral infarct. Brain Res 2007;1183:138-147.

-36 Wang Y, Deng Y, Zhou GQ: SDF-1alpha/CXCR4-mediated migration of systemically transplanted bone marrow stromal cells towards ischemic brain lesion in a rat model. Brain Res 2008;1195:104-112.

-37 Kortesidis A, Zannettino A, Isenmann S, Shi S, Lapidot T, Gronthos S: Stromal-derived factor-1 promotes the growth, survival, and development of human bone marrow stromal stem cells. Blood 2005;105:3793-3801.

-38 Xu H, Heilshorn SC: Microfluidic investigation of BDNF-enhanced neural stem cell chemotaxis in CXCL12 gradients. Small 2013;9:585-595.

39 Zhu Y, Matsumoto T, Mikami S, Nagasawa T, Murakami F: SDF1/CXCR4 signalling regulates two distinct processes of precerebellar neuronal migration and its depletion leads to abnormal pontine nuclei formation. Development 2009;136:1919-1928.

-40 Lee SH, Jin KS, Bang OY, Kim BJ, Park SJ, Lee NH, Yoo KH, Koo HH, Sung KW: Differential Migration of Mesenchymal Stem Cells to Ischemic Regions after Middle Cerebral Artery Occlusion in Rats. PLoS One 2015;10:e0134920.

41 Morimoto T, Yasuhara T, Kameda M, Baba T, Kuramoto S, Kondo A, Takahashi K, Tajiri N, Wang F, Meng J, Ji YW, Kadota T, Maruo T, Kinugasa K, Miyoshi Y, Shingo T, Borlongan CV, Date I: Striatal stimulation nurtures endogenous neurogenesis and angiogenesis in chronic-phase ischemic stroke rats. Cell Transplant 2011;20:1049-1064.

-42 Salcedo L, Lian L, Jiang HH, Sopko N, Penn M, Damaser M, Zutshi M: Low current electrical stimulation upregulates cytokine expression in the anal sphincter. Int J Colorectal Dis 2012;27:221-225.

-43 Notturno F, Pace M, Zappasodi F, Cam E, Bassetti CL, Uncini A: Neuroprotective effect of cathodal transcranial direct current stimulation in a rat stroke model. J Neurol Sci 2014;342:146-151.

44 Peruzzotti-Jametti L, Cambiaghi M, Bacigaluppi M, Gallizioli M, Gaude E, Mari S, Sandrone S, Cursi M, Teneud L, Comi G, Musco G, Martino G, Leocani L: Safety and efficacy of transcranial direct current stimulation in acute experimental ischemic stroke. Stroke 2013;44:3166-3174.

45 Adkins DL, Hsu JE, Jones TA: Motor cortical stimulation promotes synaptic plasticity and behavioral improvements following sensorimotor cortex lesions. Exp Neurol 2008;212:14-28.

46 Boychuk JA, Schwerin SC, Thomas N, Roger A, Silvera G, Liverpool M, Adkins DL, Kleim JA: Enhanced Motor Recovery After Stroke With Combined Cortical Stimulation and Rehabilitative Training Is Dependent on Infarct Location. Neurorehabil Neural Repair 2016;30:173-181. 